\title{
HLA-C, DRB1 and DQB1 alleles involved in genetic predisposition to psoriasis vulgaris in the Slovak population
}

\author{
Ivana Shawkatová • Juraj Javor • Zuzana Párnická • \\ Peter Kozub • Mária Žilínková • Peter Frey • \\ Stanislav Ferenčík • Milan Buc
}

Received: 8 July 2012 / Accepted: 11 November 2012 /Published online: 27 November 2012

(C) The Author(s) This article is published with open access at Springerlink.com 2012

\begin{abstract}
Psoriasis vulgaris is a complex chronic skin disease with immunological and genetic background. The most important predisposing genetic factors in psoriasis are genes of the human leukocyte antigen (HLA) region. Accumulative evidence has shown that several HLA alleles are closely associated with psoriasis; however, they tend to vary in different racial and ethnic backgrounds. One hundred forty-seven unrelated Slovak patients with psoriasis vulgaris (average age at onset $28 \pm 14$ years) were genotyped for the HLA-C, DQB1 and DRB1 alleles by the polymerase chain reaction using sequence-specific primers. Allele frequencies observed in the group of psoriatic patients were compared to those obtained in the ethnically matched control group comprising 194 subjects with no history of psoriasis. Susceptibility to psoriasis vulgaris in our study group is significantly associated with HLA-C*06 (odds ratio $(\mathrm{OR})=3.85$ ),
\end{abstract}

I. Shawkatová $(\bowtie) \cdot J$ J. Javor · Z. Párnická · M. Buc

Department of Immunology, Comenius University School

of Medicine, Nám. odborárov 14,

81108 Bratislava, Slovakia

e-mail: ivana.shawkatova@fmed.uniba.sk

P. Kozub

Department of Dermatovenereology, University Hospital,

Mickiewiczova 13,

81369 Bratislava, Slovakia

M. Žilínková

Dermatology Clinic, Slovak Medical University and University

Hospital, Ružinovská 6,

82606 Bratislava, Slovakia

P. Frey

Outpatient Dermatovenereology Clinic CUTIS Ltd, Nábrežná 20, 94001 Nové Zámky, Slovakia

\section{S. Ferenčík}

Institute of Immunology, University Hospital Essen,

Hufelandstr. 55,

45147 Essen, Germany
$\mathrm{DRB} 1 * 07(\mathrm{OR}=2.56)$ and $\mathrm{DQB} 1 * 02(\mathrm{OR}=1.09)$, respectively, whereas $\mathrm{DRB}^{*} 01(\mathrm{OR}=0.05)$ is associated negatively. Hereby, we provide the first report on the association of HLA-C, DRB1 and DQB1 alleles with psoriasis in the Slovak population. Our findings confirm HLA-C*06 and DRB1*07 as the most important genetic risk factors for psoriasis. However, the role of HLA genes as causative in the pathogenesis of the disease remains unclear. Identification of genetic factors that increase the risk of psoriasis is a precondition that helps to elucidate the pathogenesis of this troubling disease and identify targets for a more specific and effective therapy.

\section{Introduction}

Psoriasis vulgaris (PV) is a common chronic skin disease with a worldwide distribution, affecting 1-3\% of the general population (Henseler 1998; Kurd and Gelfand 2009). Like many other immune-mediated diseases, psoriasis results from a combined action of multiple genes and environmental triggers. The age at disease onset is highly variable; however, studies have shown that $75-90 \%$ of patients develop psoriasis before the age of 40 , with a peak around puberty and a smaller peak around 50-60 years of age (Henseler and Christophers 1985). Among psoriatic patients, up to $40 \%$ develop psoriatic arthritis (PsA) - an associated inflammation of the joints (Weger 2010).

The human leukocyte antigen (HLA) region on chromosome $6 \mathrm{p} 21$ is well known to carry the most important genetic factors in the susceptibility to psoriasis, whereas the critical segment appears to be a $300-\mathrm{kb}$ interval at the centromeric end of HLA class I, named PSORS1 (Nair et al. 2000; Martinez-Borra et al. 2003). The first reports on the association of both HLA class I and class II antigens (e.g. HLA-B13, B17, DR7) with psoriasis were obtained by 
serologic methods already in the 1970s (Russel et al. 1972; Brenner et al. 1978). In the following years, molecular genotyping was introduced, and many independent groups have proven that among HLA alleles, HLA-C*06 confers the major and most consistently demonstrated risk factor (Elder et al. 1994; Szczerkowska-Dobosz 2005; Pasic et al. 2009). HLA-C*06 carriers have a significantly higher risk of developing PV with risk ratios ranging in Caucasoid psoriatic patients from 3 to 36 (Cassia et al. 2007). However, not all HLA-C*06 psoriasis-associated haplotypes appear to confer an equal risk of $\mathrm{PV}$ in different populations as reviewed by Elder et al. (2001). Multiple HLA alleles have been identified in increased occurrence rates, most probably because of linkage disequilibrium in the HLA region. In the German, Italian and Thai population, the extended haplotype (EH) HLA-C*06-B57-DRB1*0701-DQA1*0201DQB1*0303, named according to the B allele EH-57.1, was reported to be highly overrepresented in patients with psoriasis (Schmitt-Egenolf 1996; Choonhakarn et al. 2002). Another similar predisposing haplotype, HLA-C*0602B57-DRB1*0701-DQA1*0201-DQB1*0201 (EH-57.2), was observed in Croatian patients (Kastelan et al. 2003). However, many of the associated alleles tend to vary among patients of different racial and ethnic backgrounds as reviewed by Cassia et al. (2007).

The aim of our study was to provide the first survey of the HLA-C as well as HLA-DRB1* and DQB1* allele distribution in Slovak psoriatic patients as a contribution to the precise definition of HLA class I- and class II-associated loci in different ethnic populations.

\section{Materials and methods}

\section{Study group}

One hundred forty-seven unrelated patients with chronic stable plaque PV were included in the study. They were recruited at random via several outpatient dermatovenereology clinics in Slovakia. Detailed clinical parameters of the study group were recorded by the dermatologists, and they are summarized in Table 1. Mean age at disease onset was 28 years (range 7-67, standard deviation $(\mathrm{SD}) \pm 14$ ). Of the patients, $82.3 \%$ had disease onset before 40 years of age and $17.6 \%$ after 40 . Severity and extent of the disease were estimated using the scoring system Psoriasis Area and Severity Index (PASI). The average PASI score was $22 \pm 17$.

According to the criteria proposed by Henseler and Christophers (1985), patients may be subdivided into two subsets: type I psoriasis (age at onset before 40, presence of a positive family history and strong association with HLA$\mathrm{C}^{*} 06$ ) and type II (age at onset after 40 , no family history and weak association with HLA-C*06). At first, we have
Table 1 Characteristics of the study group

\begin{tabular}{ll}
\hline Parameter & Psoriatic subjects $(n=147)$ \\
\hline Gender ratio M/F & $95 / 52$ \\
Mean age \pm SD (years) & $47 \pm 12$ \\
Mean onset age \pm SD (years) & $28 \pm 14$ \\
Onset at $\leq 40 />40$ years & $121 / 26$ \\
Familiar occurrence $+/-$ & $67 / 80$ \\
Psoriatic arthritis $+/-$ & $68 / 79$ \\
Average PASI score \pm SD & $22 \pm 17$ \\
\hline
\end{tabular}

$S D$ standard deviation, PASI Psoriasis Area and Severity Index

subdivided our patients into subsets according to the following criteria: age of onset $\leq 40$ versus $>40$ years and/or a positive family history of psoriasis versus negative history. Family history was considered positive when at least one firstor second-degree relative had psoriasis. No statistically significant differences were found when comparing the HLA allele frequencies observed in those subsets (data not shown).

Similarly, we have divided our patients into a subset with psoriatic arthritis (46.3\% of the psoriatic patients) and a subset without signs of PsA (remaining $53.7 \%$ of subjects). Again, no significant differences in frequencies were observed between the PsA-positive versus PsA-negative subsets. Therefore, we decided to report our results on the whole group of our psoriatic patients regardless of the above-mentioned criteria (Table 1).

\section{Population controls}

The reference group comprised 194 unrelated subjects without a history of PV who were randomly recruited from blood and bone marrow donors. Data on the control subjects have been reported elsewhere (Cechova et al. 1998; Kulcsarova et al. 2000). All patients and controls were Caucasoids of Slovak descent. Slovakia is a Central European country with ethnically homogenous population. Romanies who constitute a fraction of about $5 \%$ were not included in this study.

A written informed consent for enrolling in the study and for personal data management was obtained from all patients and control subjects. All investigations were carried out in accordance with the principles of the Declaration of Helsinki.

\section{HLA typing}

Both HLA class I and class II alleles were determined by molecular typing that proved superior to serological methods due to higher specificity and sensitivity (Bunce et al. 1996). DNA was extracted from whole blood using a modified salting-out procedure (Miller et al. 1988). Genotyping was performed using the PCR-SSP technique according to the 12th Workshop protocol using Olerup SSP ${ }^{\circledR}$ HLA-C low 
resolution, resp. DQ-DR SSP Combi Tray (Olerup SSP AB, Sweden) (Olerup and Zetterquist 1992; Olerup et al. 1993). Amplification reactions were prepared according to manufacturers' protocols, and electrophoresis was performed in a $1.5 \%$ agarose gel for $20 \mathrm{~min}$ at $10 \mathrm{~V} / \mathrm{cm}$.

\section{Statistical analysis}

Allele frequencies in the study group and in the controls were evaluated by direct counting. Data were tested for the goodness of fit between the observed and expected genotype frequencies, and no deviations from the Hardy-Weinberg equilibrium were found. Associations of particular alleles with psoriasis were expressed as odds ratios (OR) with $95 \%$ confidence intervals (CI) calculated according to Woolf's formula. Statistical significance of these associations was assessed using the $P$ values defined by the two-sided Fisher's exact test. As multiple comparisons were made, Bonferroni's correction was applied multiplying the obtained $P$ values by the number of alleles considered at each locus $\left(P_{\text {cor }}\right)$. The level of significance was set at $P_{\text {cor }}<0.01$. All calculations were performed using the data analysis and graphing software OriginPro version 8.1.

\section{Results}

The investigated HLA class I and class II allelic frequencies observed in 147 patients with PV and in the control group are given in Tables 2, 3 and 4. Differences between the cohorts were expressed by odds ratios and $P_{\text {cor }}$ values. They are indicated in the tables only when statistically significant, i.e. when the $P$ value corrected for the number of alleles considered at each locus was $<0.01$.
As may be seen in Table 2, the strongest association among HLA-C alleles is conferred by the $\mathrm{C}^{*} 06$ allele. The allelic frequency of $\mathrm{C}^{*} 06$ was $23.5 \%$ in patients compared to $7.5 \%$ in controls, which is an extremely statistically significant difference $\left(\mathrm{OR}=3.85, P_{\text {cor }}=0.000025\right)$. Out of the HLADRB1 alleles presented in Table 3 , only DRB $1 * 07$ was positively associated with the disease, showing a frequency of $28.9 \%$ in the patients versus $13.9 \%$ in the control group. This association is again extremely statistically significant $(\mathrm{OR}=$ $\left.2.56, P_{\text {cor }}=0.000019\right)$. On the contrary, the DRB $1 * 01$ allele was associated with $\mathrm{PV}$ negatively $\left(\mathrm{OR}=0.32, P_{\text {cor }}=0.0097\right)$. Out of the DQB1 alleles, the DQB1*02 was observed to have a significantly increased frequency in the patients $(29.3 \%$ versus $19.1 \%, \mathrm{OR}=1.09, P_{\text {cor }}=0.0095$ ) as shown in Table 4 .

We have divided our 147 patients into two subsets according to the presence $(46.3 \%)$ versus absence $(53.7 \%)$ of psoriatic arthritis. No statistically significant differences in the investigated HLA allele frequencies were observed between the two cohorts. On the contrary, significant differences were noted when each of the two subsets was compared with population controls, namely a strong positive association of HLA-C $* 06$ with psoriasis with the presence of PsA $(\mathrm{OR}=$ $\left.3.94, P_{\text {cor }}<0.0001\right)$ and a slightly weaker association with psoriasis alone $\left(\mathrm{OR}=3.72, P_{\mathrm{cor}}<0.0001\right)$. Similarly, there was a statistically significant association of HLA-DRB $1 * 07$ with psoriasis + PsA $\left(\mathrm{OR}=2.75, P_{\text {cor }}<0.0001\right)$ and a weaker association with psoriasis without $\mathrm{PsA}\left(\mathrm{OR}=2.27, P_{\text {cor }}=0.002\right)$.

\section{Discussion}

Although the aetiology of psoriasis vulgaris is still unknown, there is a common consensus that it is a complex
Table 2 Distribution of HLA-C alleles in patients with psoriasis and controls

$O R$ odds ratio, $C I$ confidence interval, $P_{\text {cor }}$ corrected $P$ value, n.s. not significant

\begin{tabular}{|c|c|c|c|c|c|c|c|}
\hline \multirow[t]{2}{*}{ HLA-C } & \multicolumn{2}{|c|}{ Psoriasis vulgaris $(2 n=294)$} & \multicolumn{2}{|c|}{ Controls $(2 n=214)$} & \multirow[t]{2}{*}{ OR } & \multirow[t]{2}{*}{$95 \% \mathrm{CI}$} & \multirow[t]{2}{*}{$P_{\text {cor }}$} \\
\hline & Count & $f(\%)$ & Count & $f(\%)$ & & & \\
\hline$* 01$ & 13 & 4.42 & 13 & 6.07 & 0.71 & $0.32-1.59$ & n.s. \\
\hline$* 02$ & 11 & 3.74 & 12 & 5.61 & 0.66 & $0.28-1.52$ & n.s. \\
\hline$* 03$ & 24 & 8.16 & 19 & 8.88 & 0.92 & $0.49-1.72$ & n.s. \\
\hline$* 04$ & 42 & 14.29 & 34 & 15.89 & 0.88 & $0.54-1.45$ & n.s. \\
\hline$* 05$ & 10 & 3.40 & 9 & 4.21 & 0.80 & $0.32-2.00$ & n.s. \\
\hline$* 06$ & 69 & 23.47 & 16 & 7.48 & 3.85 & $2.13-6.67$ & $<0.0001$ \\
\hline$* 07$ & 50 & 17.01 & 58 & 27.10 & 0.55 & $0.36-0.85$ & n.s. \\
\hline$* 08$ & 2 & 0.68 & 7 & 3.27 & 0.20 & $0.04-0.99$ & n.s. \\
\hline$* 12$ & 52 & 17.69 & 32 & 14.95 & 1.22 & $0.76-2.00$ & n.s. \\
\hline *14 & 1 & 0.34 & 0 & 0 & 2.19 & $0.09-54.12$ & n.s. \\
\hline$* 15$ & 4 & 1.36 & 3 & 1.40 & 0.97 & $0.22-4.35$ & n.s. \\
\hline$* 16$ & 13 & 4.42 & 4 & 1.87 & 2.44 & $0.78-7.69$ & n.s. \\
\hline$* 17$ & 1 & 0.34 & 5 & 2.34 & 0.14 & $0.02-1.23$ & n.s. \\
\hline$* 18$ & 2 & 0.68 & 2 & 0.93 & 0.72 & $0.10-5.26$ & n.s. \\
\hline
\end{tabular}


Table 3 Distribution of HLADRB1 alleles in patients with psoriasis and controls
$O R$ odds ratio, $C I$ confidence interval, $P_{c o r}$ corrected $P$ value, n.s. not significant

\begin{tabular}{|c|c|c|c|c|c|c|c|}
\hline \multirow[t]{2}{*}{ HLA-DRB1 } & \multicolumn{2}{|c|}{ Psoriasis vulgaris $(2 n=294)$} & \multicolumn{2}{|c|}{ Controls $(2 n=388)$} & \multirow[t]{2}{*}{ OR } & \multirow[t]{2}{*}{$95 \% \mathrm{CI}$} & \multirow[t]{2}{*}{$P_{\text {cor }}$} \\
\hline & Count & $f(\%)$ & Count & $f(\%)$ & & & \\
\hline$* 01$ & 11 & 3.74 & 42 & 10.82 & 0.32 & $0.16-0.64$ & $<0.001$ \\
\hline$* 03$ & 20 & 6.80 & 31 & 7.99 & 0.84 & $0.47-1.52$ & n.s. \\
\hline *04 & 26 & 8.84 & 35 & 9.02 & 0.98 & $0.57-1.67$ & n.s. \\
\hline$* 07$ & 85 & 28.91 & 54 & 13.93 & 2.56 & $1.72-3.70$ & $<0.0001$ \\
\hline *08 & 8 & 2.72 & 10 & 2.58 & 1.05 & $0.41-2.70$ & n.s. \\
\hline *09 & 2 & 0.68 & 1 & 0.26 & 2.63 & $0.24-33.33$ & n.s. \\
\hline$* 10$ & 4 & 1.36 & 4 & 1.03 & 1.33 & $0.33-5.26$ & n.s. \\
\hline$* 11$ & 36 & 11.57 & 63 & 16.24 & 0.72 & $0.46-1.12$ & n.s. \\
\hline$* 12$ & 13 & 4.42 & 5 & 1.29 & 3.57 & $1.25-10.00$ & n.s. \\
\hline$* 13$ & 38 & 12.93 & 56 & 14.43 & 0.88 & $0.56-1.37$ & n.s. \\
\hline$* 14$ & 11 & 3.74 & 11 & 2.83 & 1.33 & $0.57-3.13$ & n.s. \\
\hline$* 15$ & 23 & 7.82 & 52 & 13.40 & 0.55 & $0.33-0.92$ & n.s. \\
\hline$* 16$ & 19 & 6.47 & 24 & 6.18 & 1.05 & $0.56-1.96$ & n.s. \\
\hline
\end{tabular}

disorder occuring in a sensitive genetic territory. Multiple genes seem to be involved in the pathogenesis of psoriasis; however, the major genetic determinant is located within the PSORS1 segment of the HLA region on chromosome $6 \mathrm{p} 21.3$, as reported by several independent groups (Nair et al. 2000; Martinez-Borra et al. 2003).

Our study confirmed the strong positive association of psoriasis with HLA-C*06, observed mainly in Caucasoid populations as well as in several other ethnically different groups. There are only a few studies from oriental populations, e.g. the Japanese reported association with other HLA-C alleles, most often with the HLA-C*07 allele (Roitberg-Tambur et al. 1994; Asahina et al. 1996). Interestingly, the occurrence rate of HLA-C*07 was increased also in our psoriatic patients, though only on the edge of the statistical significance $\left(P_{\text {cor }}=0.07\right)$.

The HLA-C*06 allelic frequency of $23.5 \%$ observed in our psoriatic subjects (compared to $7.5 \%$ in the controls) highly corresponds with that of $23.9 \%$ observed in the PV patients of neighbouring Poland and fits into the general image seen in the Central European geographic region (Szczerkowska-Dobosz et al. 1996; Łuszczek et al. 2003).
Though HLA-C*06 is undoubtedly associated with PV, limited data exist to explain the functional role of HLA-C in the pathogenesis of psoriasis. According to many researchers, it is unlikely that HLA-C itself is the susceptibility gene (Elder et al. 2001; Orru et al. 2005; Pasic et al. 2009). HLA-C is most probably a marker of another closely linked gene, or a block of genes at a distinct locus. Thus, major effort has been put into the identification of candidate genes close to HLA-C such as the corneodesmosin gene, which encodes an adhesive protein expressed by keratinocytes or the alpha-helix coiled-coil rod homologue gene. However, there is a lack of evidence confirming their direct involvement in the development of psoriasis, and none of the candidates are convincingly associated with psoriasis independent of HLA-C (Tazi-Ahnini et al. 1999; O'Brien et al. 2001; Capon et al. 2002, 2003).

The HLA-C*06 allele is the only genetic variant repeatedly observed to be associated with the phenotypic features of PV, especially with an early onset of the disease as confirmed among others by Szczerkowska-Dobosz et al. (2004). According to Henseler and Christophers (1985), patients may be classified into two distinct types: type I (age at disease onset before 40 years, familial occurrence
Table 4 Distribution of HLADQB1alleles in patients with psoriasis and controls

$O R$ odds ratio, $C I$ confidence interval, $P_{\text {cor }}$ corrected $P$ value, n.s. not significant

\begin{tabular}{|c|c|c|c|c|c|c|c|}
\hline \multirow[t]{2}{*}{ HLA-DQB1 } & \multicolumn{2}{|c|}{$\begin{array}{l}\text { Psoriasis vulgaris } \\
(2 n=294)\end{array}$} & \multicolumn{2}{|c|}{$\begin{array}{l}\text { Control subjects } \\
(2 n=388)\end{array}$} & \multirow[t]{2}{*}{ OR } & \multirow[t]{2}{*}{$95 \% \mathrm{CI}$} & \multirow[t]{2}{*}{$P_{\text {cor }}$} \\
\hline & Count & $f(\%)$ & Count & $f(\%)$ & & & \\
\hline *05 & 51 & 17.35 & 85 & 21.91 & 0.66 & $0.45-0.97$ & n.s. \\
\hline$* 06$ & 50 & 17.00 & 92 & 23.71 & 1.75 & $1.23-2.50$ & n.s. \\
\hline *02 & 86 & 29.25 & 74 & 19.07 & 1.09 & $0.79-1.49$ & $<0.01$ \\
\hline$* 03$ & 103 & 35.04 & 129 & 33.25 & 0.66 & $0.20-2.22$ & n.s. \\
\hline *04 & 4 & 1.36 & 8 & 2.06 & 0.75 & $0.51-1.10$ & n.s. \\
\hline
\end{tabular}


and high frequency of HLA-C*06) and type II psoriasis (age at onset after 40, occuring sporadically, characterized by a weak association with HLA-C*06). However, it proved difficult to classify our subjects as either having the type I or type II psoriasis as many patients were in an intersection of the two types showing features of both groups, and thus, we failed to confirm this observation. Comparison of the two types was also limited by the fact that we had only a relatively small fraction of late-onset patients $(17.6 \%)$.

In order to determine whether HLA-C*06 and, respectively, other alleles are associated with PsA itself or primarily with psoriasis, we have compared the allele frequencies obtained in psoriatic patients with PsA with frequencies in patients having psoriasis alone. Our results suggest that the primary association with HLA-C*06 and HLA-DRB1*07 is with psoriasis and not with PsA per se.

Significant overrepresentation of the neighbouring HLA class II alleles, namely the DRB $1 * 07$ and DQB $1 * 02$ in our study group, is most probably due to the fact that they are contained within the same extended haplotype. This particular risk haplotype was observed also in Croatian psoriasis patients and was named EH-57.2 (Kastelan et al. 2003).

Many authors have reported some alleles that occur in lower occurrence rates in patients with PV, indicating they may have a protective effect (Cassia et al. 2007; Kundakci et al. 2002; Luszczek et al. 2003). The only allele with a significantly decreased frequency in our patients was the HLA-DRB ${ }^{*} 01\left(\mathrm{OR}=0.32, P_{\text {cor }}<0.001\right)$. However, as the palette of published "protective" alleles is very variegated and they show only mild association, we assume that they occur at the expense of the highly overrepresented predisposing alleles.

In conclusion, our study provides the first report on HLA class I and class II allele association with psoriasis vulgaris in the Slovak population. Our data point toward the alleles HLA$\mathrm{C}^{*} 06$, DRB $1 * 07$ and $\mathrm{DQB} 1 * 02$, respectively, as major genetic risk factors for PV. Precise identification of genetic factors that increase the risk of psoriasis and psoriatic arthritis will help to elucidate the pathogenesis of this troubling disease and identify targets for a more specific and effective therapy.

Acknowledgments This study was supported by the VEGA grant of the Ministry of Education of the Slovak Republic No. 1/0145/09. Mrs. B. Faragova is gratefully acknowledged for her technical assistance.

Conflict of interest The authors declare that they have no conflict of interest.

Open Access This article is distributed under the terms of the Creative Commons Attribution License which permits any use, distribution, and reproduction in any medium, provided the original author(s) and the source are credited.

\section{References}

Asahina A, Kuwata S, Tongunaga K et al (1996) Study of aspartate at residue 9 of HLA-C molecules in Japanese patients with psoriasis vulgaris. J Dermatol Sci 13:125-133

Brenner W, Gschnait F, Mayr RW (1978) HLAs B13, B17, B37 and Cw6 in psoriasis vulgaris: association with age of onset. Arch Dermatol Res 262:337-339

Bunce M, Barnardo MCNM, Procter J et al (1996) High resolution HLA-C typing by PCR-SSP: identification of allelic frequencies and linkage disequilibria in 604 unrelated random UK Caucasoids and a comparison with serology. Tissue Antigens 48:680-691

Capon F, Munro M, Barker J, Trembath R (2002) Searching for the major histocompatibility complex psoriasis susceptibility gene. J Invest Dermatol 118:745-771

Capon F, Toal IK, Evans JC et al (2003) Haplotype analysis of distantly related populations implicates corneodesmosin in psoriasis susceptibility. J Med Genet 40:447-452

Cassia FF, Carneiro SC, Marques MTQ et al (2007) Psoriasis vulgaris and human leukocyte antigens. J Eur Acad Dermatol Venereol 21:303-310

Cechova E, Fazekasova H, Ferencik S, Shawkatova I, Buc M (1998) HLA-DRB1, -DQB1 and -DPB1 polymorphism in the Slovak population. Tissue Antigens 51:574-576

Choonhakarn C, Romphruk A, Puapairoj C (2002) Haplotype associations of the major histocompatibility complex with psoriasis in Northeastern Thais. Int J Dermatol 41:330-334

Elder JT, Nair RP, Voorhees JJ (1994) Epidemiology and the genetics of psoriasis. J Invest Dermatol 102:24-27

Elder JT, Nair RP, Henseler T et al (2001) The genetics of psoriasis 2001: the odyssey continues. Arch Dermatol 137:1447-1454

Henseler T (1998) The genetics of psoriasis. Arch Dermatol Res 290:463-476

Henseler T, Christophers E (1985) Psoriasis of early and late onset: characterization of two types of psoriasis vulgaris. J Am Acad Dermatol 3:450-456

Kastelan M, Gruber F, Cecuk-Jelicic E et al (2003) A new extended haplotype Cw*0602-B57-DRB1*0701-DQA1*0201DQB $1 * 0201$ associated with psoriasis in the Croatian population. Clin Exp Dermatol 28:200-202

Kulcsarova E, Buc M, Ferencik S (2000) HLA-A, HLA-B and HLA-C polymorphism in the Slovak population. Folia Biologica (Praha) 46:153-156

Kundakci N, Oskay T, Olmez U et al (2002) Association of psoriasis vulgaris with HLA class I and class II antigens in the Turkish population, according to the age at onset. Int J Dermatol 41:345-348

Kurd SK, Gelfand JM (2009) The prevalence of previously diagnosed and undiagnosed psoriasis in US adults: results from NHANES 2003-2004. J Am Acad Dermatol 60:218-224

Luszczek W, Kubicka W, Cislo M et al (2003) Strong association of HLA-Cw6 allele with juvenile psoriasis in Polish patients. Immunol Lett 85:59-64

Martinez-Borra J, Gonzalez S, Santos-Juanes J et al (2003) Psoriasis vulgaris and psoriatic arthritis share a $100 \mathrm{~kb}$ susceptibility region telomeric to HLA-C. Rheumatology 42:1089-1092

Miller SA, Dykes DD, Polesky HF (1998) A simple salting out procedure for extraction of high molecular weight DNA from human nucleated cells. Nucl Acids Res 16:1215

Nair RP, Stuart P, Henseler T et al (2000) Localization of psoriasissusceptibility locus PSORS1 to a $60-\mathrm{kb}$ interval telomeric to HLA-C. Am J Hum Genet 66:1833-1834

O'Brien KP, Holm SJ, Nilsson S et al (2001) The HCR gene on 6p21 is unlikely to be a psoriasis susceptibility gene. J Invest Dermatol 116:750-754 
Olerup O, Zetterquist H (1992) HLA-DR typing by PCR amplification with sequence specific primers (PCR-SSP) in $2 \mathrm{~h}$ An alternative to serological DR typing in clinical practice including donorrecipient matching in cadaveric transplantation. Tissue Antigens 39:225-235

Olerup O, Aldener A, Fogdell A (1993) HLA-DQB1 and DQA1 typing by PCR amplification with sequence specific primers (PCR-SSP) in $2 \mathrm{~h}$. Tissue Antigens 41:119-134

Orru S, Giuressi E, Carcassi C et al (2005) Mapping of the major psoriasis-susceptibility locus (PSORS1) in a $70-\mathrm{Kb}$ interval around the corneodesmosin gene (CDSN). Am J Hum Genet $76: 164-171$

Pasic A, Lipozencic J, Ceovic R, Kostovic K (2009) The genetics of psoriasis - selected novelties in 2008. Acta dermatovenerologica Croatica 17:176-181

Roitberg-Tambur A, Friedman A, Tzfoni EE et al (1994) Do specific pockets of HLA-C molecules predispose Jewish patients to psoriasis vulgaris? J Am Acad Dermatol 31:964-968

Russel JT, Schultes ML, Kuban DJ (1972) Histocompatibility antigens associated with psoriasis. N Engl J Med 287:738-739
Schmitt-Egenolf M (1996) Familial juvenile onset psoriasis is associated with the human leukocyte antigen (HLA) class I side of the extended haplotype Cw6-B57-DRB1*0701-DQA1*0201-DQB1*0303: a population- and family-based study. J Invest Dermatol 106:711-714

Szczerkowska-Dobosz A (2005) Human leukocyte antigens as psoriasis inheritance and susceptibility markers. Arch Immunol Ther Exp (Warsz) 53:428-433

Szczerkowska-Dobosz A, Placek W, Szczerkowska Z et al (1996) Psoriasis vulgaris with the early and late onset-HLA phenotype correlations. Arch Immunol Ther Exp (Warsz) 44:265-269

Szczerkowska-Dobosz A, Rebala K, Szczerkowska Z, Witkowska-Tobola A (2004) Correlation of HLA-Cw*06 allele frequency with some clinical features of psoriasis vulgaris in the population of nothern Poland. J Appl Genet 45:473-476

Tazi-Ahnini R, Camp NJ, Cork MJ et al (1999) Novel genetic association between the corneodesmosin (MHC S) gene and susceptibility to psoriasis. Hum Mol Genet 8:1135-1140

Weger W (2010) Current status and new developments in the treatment of psoriasis and psoriatic arthritis with biological agents. $\mathrm{Br} \mathrm{J}$ Pharmacol 160:810-820 